\title{
Entrevista Com Editores da Revista Psicologia: Ciência e Profissão
}



A proposta desta entrevista foi reunir todos os nove editores que teve a revista Psicologia: Ciência e Profissão desde a sua criação para que contassem um pouco de seu trabalho. Oito dos nove ex-editores puderam ser contatados, e estiveram presentes à gravação os professores João Cláudio Todorov, Antônio Marcos Chaves, Marilene Proença, além de membros da comissão editorial atual (Acácia Angeli dos Santos, Henrique Figueiredo Carneiro, Inara Barbosa Leão, Iracema Neno Cecílio Tada e Paulo Menandro).

Leia abaixo a entrevista, realizada na sede do Conselho Federal de Psicologia, em Brasília, no mês de junho de 2010.

Paulo Menandro - Começamos solicitando ao professor João Cláudio informações a respeito da ideia da criação da revista. Como apareceu? Naquele contexto, o que havia? Por que essa ideia de publicar uma revista dentro do Conselho Federal de Psicologia? E como foi o trabalho inicial de organização?

João Cláudio Todorov - A ideia de uma revista que fosse enviada a todos os psicólogos era mais ou menos unânime no Conselho Federal de Psicologia (CFP); pensava-se em um meio de comunicação, mas pensava-se mais em um boletim de comunicação aos psicólogos e em instruções sobre as resoluções. Era o segundo plenário do Conselho, muita coisa ainda tinha de ser definida e muita coisa foi definida nesses seis anos que eu passei no Conselho, de 1976 a 1982. Então, a ideia era uma revista mais voltada para orientação aos profissionais de Psicologia. Só que tinha uma pedra no sapato de todo mundo, que era eu (risos). Eu não combinava com 
a posição do Conselho. Naquela época, em 1978, eu fui o primeiro presidente da Associação dos Docentes pela Universidade de Brasília (UnB), em plena ditadura, e convivi, aqui no Conselho, com pessoas que não eram da mesma linha política. Além disso, eu ficava fora do perfil porque era o único a trabalhar com pesquisa básica. Tinha dedicação exclusiva na UnB, trabalhando com pesquisa básica, publicando em pesquisa básica. E, no Brasil, na época, não havia periódicos científicos. Existia o Arquivos Brasileiros de Psicologia Aplicada, que era um boletim. Havia outros que não tinham muita periodicidade, todos pelejavam com problema de recursos, e aqui teríamos uma revista na qual os recursos estariam garantidos. A ideia era garantir uma revista equilibrada, por isso sugeri o nome Psicologia: Ciência e Profissão, a fim de garantir espaço para a publicação de pesquisas básicas e aplicadas, e não apenas de artigos de resenha ou históricos.

Sempre fui contra fazer um número zero, e, por mim, ele não teria saído assim. Mas saiu porque o (Antonio) Rodrigues tinha um artigo para publicar. Eu já estava acostumado a publicar e sabia como era a rotina de revista séria, então sabíamos que precisávamos, primeiro, formar o conselho editorial. Mas, afinal, (o artigo do Rodrigues) era um trabalho interessante de História, que estava pronto, e não tinha sentido esperar para passar por um conselho editorial, então se resolveu fazer um número zero com artigos de convidados. Eu corro um sério risco de falsas memórias, porque meu ego é do tamanho de um bonde. Não garanto, mas acho que convidei o (Luiz) Pasquali, que havia escrito uma das melhores coisas que tínhamos para mostrar: "Isso é pesquisa, interessa a todo mundo", e que daria uma amostra do que poderia vir para a revista. Tenho a impressão de que o número zero foi construído mais ou menos assim. A Eunice (Maria Lima Soriano Alencar), que era representante do CRP 01 e secretária do conselho editorial, também não se lembra muito. Lembro-me dessas discussões no plenário, mas, depois, de fato, a montagem da revista foi um custo. Agora descobri que está tudo on line, e descobri que tenho os originais. Levou umas duas semanas para eu botar a cabeça para funcionar e ver onde é que estavam as coisas.

Resumindo, é isso. A revista surge da necessidade de comunicação direta do Conselho com os psicólogos, que foi unânime. A ideia de um conselho editorial representativo de todos os Regionais, também. Acho que ela começou com essas características, não me lembro muito mais do que isso.

Paulo Menandro - A comissão editorial inicial não tinha envolvimento direto com a diretoria do CFP na época? Nem todas essas pessoas estavam naquela diretoria?

João Cláudio Todorov - Não, cada membro do conselho editorial era indicado pelo seu Conselho Regional, e eu era indicado pelo Conselho Federal como editor. Acho que há muito folclore no meio disso. Fiquei meio chateado uma vez, não vou dizer com quem, mas o pessoal dizendo que, antes de 1985, não interessava a história do Conselho, e que todo mundo era de direita. Eu só não digo o que penso em respeito aos presentes. Vai ser de direita na UnB! Em 74, assumi o Regional, e nem todo mundo era de direita naquela época.

Iracema Neno Cecílio Tada - O senhor disse que as pessoas foram convidadas a fazer os artigos da edição número zero. $\mathrm{E}$ depois, para o número 1 e para o número 2 , como foi o processo?

João Cláudio Todorov - Depois o conselho editorial funcionou. Você não monta uma revista em lugar nenhum se não ficar telefonando para os amigos e dizendo: "Vê se você tem alguém com algum artigo para 
submeter". Isso eu faço até hoje. Para a última gracinha minha, que é a Revista Brasileira de Análise de Comportamento, eu mando e-mail para os meus amigos; quando não tem artigo no Brasil, eu mando para os de fora perguntando se têm algo para publicar. É assim que você mantém uma periodicidade, porque a pior coisa que pode acontecer com qualquer revista é não ter o que publicar, atrasar. Isso a desmoraliza.

\section{Acácia Aparecida Angeli dos Santos -} Antônio Marcos, conte um pouco para nós como foi esse outro período, já na década de 90, quando você assumiu o Conselho e também foi editor da revista.

Antônio Marcos Chaves - A memória também não está muito atualizada. Vou resgatar um pouco desse período de 1990 a 1992 e falar alguma coisa de 1996. Fui editor em 96, mas fui do plenário de 90 a 92 e fui presidente do CFP em 92. Nesse período de 90 a 92, o editor sempre foi o José Estanislau Vilela. Aquele era um momento importante para o Brasil e para a Psicologia, importante para o Brasil, porque estávamos saindo da ditadura e haveria a primeira eleição direta. Eu votaria pela primeira vez para presidente! E isso, é lógico, mobilizava todas as categorias profissionais, inclusive a dos psicólogos. Era importante para a profissão, porque passávamos de um momento em que não tínhamos muita liberdade e havia poucos espaços de atuação, e começamos a ter discussões mais interessantes acerca da Psicologia como ciência e da Psicologia como profissão. Foi nesse momento que começamos a ocupar espaços que não eram exclusivamente a clínica, a organização ou a escola. Foram abertos muitos espaços. Lembro-me com bastante saudade de ter participado, como presidente do CFP, da $1^{a}$ Conferência Nacional de Saúde Mental. Foi quando começaram também as conferências, porque o Brasil estava se redemocratizando. O que percebíamos é que isso tudo mexia muito com a profissão e com a formação. Acho que uma característica dos plenários (do CFP) e dos artigos submetidos e aprovados é que a maior parte é constituída por professores universitários. Os plenários também são constituídos por muitos professores universitários, muitos deles com dedicação exclusiva e pesquisadores. Então, a revista passa a ter uma presença muito grande de pesquisadores e pouca participação dos psicólogos, e o seu objetivo era os dois lados. Naquele momento, tínhamos esse problema, e vínhamos procurando solucioná-lo. Uma das vias era mandar a revista para todos os psicólogos, então, eventualmente, algum profissional que não era acadêmico enviava um artigo, um relato de experiência, mas com um escopo que não era muito adequado às publicações científicas. Outro problema que tínhamos na época, de 90 a 92, era estarmos com a revista muito atrasada. Vários volumes não tinham sido publicados, e isso trazia problemas para os arquivos das bibliotecas em termos de seriação, de catalogação, uma série de coisas que as bibliotecárias das universidades reclamavam. Uma das soluções foi atualizar a publicação dos volumes e publicar vários volumes em um mesmo número. Observamos também que gradativamente havia maior participação dos psicólogos submetendo artigos. A comissão editorial funcionava bem, e, nesse momento, começamos uma transição em relação à - como hoje dizemos - formatação da revista, para que ela tivesse um caráter de publicação mais de acordo com a atualidade das revistas científicas, em termos de uma ordem de resumo. Isso depende da categoria da publicação, mas foi tentado naquele momento de forma que se tivesse uma revista com boa aceitabilidade pelos pesquisadores e, inclusive, pelas agências de fomento.

Fiz um levantamento tentando mostrar que havia uma mudança naquela época. Depois mudou muito mais, mas, por exemplo, naquele momento, houve um número de artigos apenas 
O que posso dizer é que o Sistema Conselhos de Psicologia passa a ter um engajamento de prática política mais evidente, 0 que é bastante lógico, porque estávamos saindo da ditadura.

Antônio Marcos Chaves sobre excluídos, com a participação de alguns profissionais, e outros sobre deficientes, sem teto, oprimidos e marginalizados. Nos 30 anos de regulamentação da profissão, trabalhamos com alguns artigos sobre as práticas dos psicólogos, sobre a ética, sobre transferência e transferências, psicoterapia psicanalítica, supervisão em Psicologia e o psicólogo nas organizações. O volume posterior foi dedicado praticamente a dois grandes psicólogos brasileiros, Ulisses Pernambucano e Helena Antipoff, tentando resgatar um pouco da história da construção da Psicologia, e com mais alguns artigos que tiveram a influência desses professores, pesquisadores, em alguma época. Assim, tentamos começar a organizar a revista por temas e de forma que atendesse às necessidades da comunidade.

Henrique Figueiredo Carneiro - A revista nasceu com a perspectiva de cobrir um referencial para a Psicologia em função da ciência e da profissão, mas, com o que você acabou de dizer, ocorreu-me que, permeando essa referência, havia uma questão política que, digamos, costurava essa referência da ciência e da profissão. Como essas experiências de editoria começaram realmente a tomar isso como um ponto importante da produção dos artigos que foram publicados na revista? Essa pergunta vale para os nossos três convidados.

Antônio Marcos Chaves - O que posso dizer é que o Sistema Conselhos de Psicologia passa a ter um engajamento de prática política mais evidente, o que é bastante lógico, porque estávamos saindo da ditadura. Um pouco antes da década de 90, entra-se na luta pelos trabalhadores, por exemplo, o que o Conselho não tinha tradição de fazer. O papel do Conselho, que é o de orientar e fiscalizar a profissão, passa a incluir também o de construção da cidadania. Essa foi uma das coisas importantes da época, e quer dizer, temos de trabalhar de uma forma que não precisemos mais de Conselho, de fiscalização e de orientação, ou seja, vamos lutar por uma sociedade que tenha cidadãos, porque o cidadão conhece os seus direitos. Ele não precisa que alguém diga a ele o que o psicólogo vai fazer ou não. Na verdade, é algo contraditório, porque, à medida que a sociedade se torna mais cidadã, com indivíduos que conhecem seus direitos, não é mais necessário um órgão estatal para fiscalizar a profissão. Tínhamos também o Conselhão, a reunião dos presidentes de todos os Conselhos Federais, que ocorria periodicamente e na qual discutíamos as políticas de atuação desses Conselhos. Essa inserção, eu acho, é diferenciada. Isso evoluiu muito, e hoje o Sistema Conselhos está perfeitamente engajado nos direitos humanos, na luta antimanicomial, na luta contra o racismo, enfim, em todas essas demandas políticas da sociedade.

Esqueci-me de fazer um comentário antes, relacionado à pergunta anterior. A revista Paulo Menandro falou um pouco sobre isso - sempre foi muito importante para os psicólogos tomarem conhecimento do que estava acontecendo, mas não foi muito importante para eles se atualizarem. Ela sempre foi e é muito importante para os estudantes de graduação do curso de Psicologia e de pós-graduação. Conheço muitos professores que utilizavam artigos da revista Psicologia: Ciência e Profissão para discussão com os seus estudantes.

Paulo Menandro - Mas, Antônio Marcos, esses números que você citou, eu me lembro deles, eram quase temáticos. Eles tinham entrevistas, tinham algumas coisas curtas, tinha esse número sobre excluídos, sem teto, um só sobre crianças. Essa decisão era do conselho editorial? Isso não era uma decisão do Conselho Federal? O conselho editorial definia isso previamente ou isso decorria de um conjunto de contribuições que já estavam presentes, que permitiam uma reunião desses 
Nos seis primeiros anos, era um pessoal todo de direita, Arena da cabeça aos pés. Então, não se pode esperar discutir política. Eles nem sabiam o que eu fazia na UnB.

\section{João Cláudio Todorov}

textos? Esses textos, parece-me, mostram uma questão que permaneceu muito tempo ainda e que só recentemente foi resolvida, se a revista tendia mais para a profissão ou mais para a pesquisa. O próprio Conselho acabou tomando a decisão de que a revista é de pesquisa, e outras publicações vão fazer um pouco aquele papel que a revista fazia duplamente. Então, gostaria de saber se era o conselho editorial que definia isso ou se isso acontecia quase que por acaso em função do conjunto de contribuições que estavam ali reunidas e aí, a partir disso, se decidia montar aquele número.

Antônio Marcos Chaves - Não me lembro exatamente como era o trânsito disso. Em função de todo esse envolvimento político do Conselho, a temática da revista era definida no plenário do Conselho Federal de Psicologia. O conselho editorial tinha o papel de receber os artigos e avaliar como se enquadrariam naquela temática proposta. Essas temáticas surgiam na plenária do Federal a partir da discussão política que se fazia. Há um tema importante? Nós estamos participando disso? Vamos tentar ver como o psicólogo está discutindo isso.

João Cláudio Todorov - A Lei que institui o Conselho é de 1962, e o primeiro plenário deveria ter sido estabelecido logo depois, mas foi uma batalha razoável das lideranças da época para que de fato o fosse. Eu me lembro que, aqui de Brasília, dois membros do primeiro (plenário do Conselho) Federal eram um deputado gaúcho, Clóvis Stenzel, da direita impecável, e o Geraldo Serpro, porque foram essas lideranças de direita que conseguiram, de alguma forma, aprovar a lei que criou o Conselho. Nos seis primeiros anos, era um pessoal todo de direita, Arena da cabeça aos pés. Então, não se pode esperar discutir política. Eles nem sabiam o que eu fazia na UnB.
Paulo Menandro - Sobre os números iniciais da revista: por que saiu um número em 79 , dois em 81 e dois em 83? O que causou esse hiato? Era devido a essa questão da inexistência de artigos?

João Cláudio Todorov - O que me lembro era de sair caçando artigos. Na época, não era falta de dinheiro, era falta de artigo, mesmo.

Paulo Menandro - Vamos dar um salto no tempo. A Marilene Proença disse que, em dado momento, o Conselho fez uma pesquisa sobre os produtos (de comunicação) do CFP que os psicólogos conheciam, e a revista ficou muito bem situada. Gostaríamos que contasse isso, que foi exatamente na época em que ela estava no comando da revista.

Marilene Proença - Fui editora da revista Psicologia: Ciência e Profissão de 2002 a 2004, e tive a chance de suceder o professor Sérgio Leite, que havia realizado um trabalho muito interessante de discussão e organização da composição da comissão editorial e de trabalho coletivo. Reuníamo-nos periodicamente, todo o grupo editorial, concebendo a revista como um todo. Passávamos dois ou três dias em Brasília, semestralmente, trabalhando coletivamente com os artigos, com os pareceres, podendo avaliar cada número da revista. Montávamos os quatro números da revista praticamente nessa reunião da comissão editorial.

Nessa época, o Conselho Federal de Psicologia considerou importante fazer uma pesquisa que atualizasse a discussão a respeito do perfil profissional do psicólogo brasileiro, já realizada em outra ocasião e atualizada naquela gestão. Dentro das perguntas que eram feitas ao psicólogo, havia uma questão espontânea que se referia a qual produto que o Conselho Federal ofertava e o psicólogo conhecia. A revista foi o primeiro produto mais mencionado espontaneamente pelos psicólogos como algo que, realmente, 
definia uma atuação do Conselho Federal de Psicologia. E a pesquisa foi importante nessa época, porque, entre esses momentos de avaliação do lugar institucional da revista, da relevância dessa forma de publicação para os psicólogos, foi constituído um grupo de trabalho do Conselho Federal, montado por vários Conselhos Regionais, que tinha a seguinte pergunta: "Os meios de divulgação que nós temos hoje para os psicólogos brasileiros são suficientes, realmente, para levar aos psicólogos as questões que o Conselho Federal e os psicólogos brasileiros têm constituído ou construído socialmente?", quer dizer, a revista é um bom meio de divulgação da Psicologia brasileira ou teríamos que criar outras formas de divulgação? Essa discussão veio da seguinte maneira: temos, então, a chamada Conta Revista no Sistema Conselhos, que é voltada para a produção desse material de divulgação do Conselho Federal. Como estamos utilizando essa Conta Revista? Estamos conseguindo, realmente, atingir o psicólogo com esses meios de divulgação que temos? Em função dessa discussão, a revista, evidentemente, entra em pauta, e há vários questionamentos de diversas naturezas. Será que ela não é uma revista acadêmica, na qual somente os profissionais das universidades publicam? Ela é uma revista que está nos consultórios, que está nas unidades básicas de saúde, que está no dia a dia do psicólogo ou está somente nos cursos de formação de Psicologia? E esse custo que ela tem, possui um retorno compatível? Na época, os quatro números custavam em torno de um milhão de reais por ano. Era um custo que deveria ser bancado por essa Conta Revista ou deveriam ser instituídas outras formas de divulgação além dessa que pudessem distribuir melhor esses recursos? Todas essas questões foram postas em pauta, e, na ocasião, tive a ideia de realizar, como editora, um levantamento de dez números da revista, para termos algum dado sobre o perfil da publicação: quais eram os temas publicados, se eram temas de profissão, de ciência e profissão ou de ciência. Ela é uma revista que tem um caráter mais científico ou científico profissional ou mais profissional? Será que realmente só publicam professores das universidades ou há outros segmentos da Psicologia também presentes nesses números? Fizemos esse trabalho, com a ajuda de Flavia Asbahr, uma de minhas orientandas de mestrado, de caráter pontual, mas os dados foram interessantes, porque mostraram que em torno de $70 \%$ dos artigos publicados na revista se referiam ao tema ciência e profissão; só um pequeno grupo era ciência stricto sensu, e outro tanto artigos voltados para experiências e relatos de experiências profissionais. Nessa discussão, também verificamos que havia muitos psicólogos que publicavam na revista, não só os professores de cursos de graduação e pósgraduação em Psicologia, mas também alunos de graduação junto com professores, pessoas que trabalhavam em unidades básicas de saúde, na área de saúde mental e que queriam discutir uma dada problemática que estava acontecendo na sua região. A revista de fato apresentava um caráter nacional, conseguia representar todos os Estados brasileiros e era muito plural, do ponto de vista das abordagens em Psicologia. Tínhamos toda a diversidade da Psicologia contida no interior da publicação. Além disso, era o momento em que havia a realização das primeiras revistas eletrônicas em Psicologia. Em 2003, se não me falha a memória, houve um evento internacional na UnB, mostrando a importância das revistas eletrônicas, o quanto elas entrariam, a partir desse momento, como a grande opção de publicação e de processo de avaliação dos manuscritos. No bojo dessa discussão do grupo de trabalho sobre a revista, houve a decisão de que ela fosse transformada em uma revista eletrônica para todos os psicólogos, ampliando o acesso, inclusive, para os estudantes de Psicologia, porque só os psicólogos recebiam a revista em papel, e, ao mesmo tempo, mantinham uma tiragem em papel que seria para as bibliotecas, para 
as instituições cadastradas no Conselho Federal de Psicologia, para os autores e para os pareceristas, enfim, para os colaboradores da revista.

Inara Barbosa Leão - É possível fazerem um balanço, uma avaliação de como percebem a questão das temáticas que passam durante todo esse tempo pela revista? Elas ainda guardam essa relação tão direta com a situação do País, com as temáticas mais importantes?

João Cláudio Todorov - Vou fazer um apanhado geral de como vejo a evolução da revista. Aquilo que eu pensava acabou se realizando em termos de garantir que o Conselho Federal de Psicologia olharia para a profissão não só como atuação do profissional mas preocupado com a formação do profissional e da Psicologia como ciência. Esse levantamento que a Marilene fez é fantástico, de que a maior parte dos artigos tem esses dois aspectos. Eu não vejo a Psicologia, dois pontos, ciência ou profissão, eu coloquei e profissão no sentido de que as duas coisas estão juntas, e fico bastante contente com isso. A revista, assim como a composição do Conselho, foi refletindo as mudanças que ocorreram no País. A partir do momento em que várias revistas científicas começam a aparecer, o espaço para a pesquisa básica aparece em diversos outros lugares. Artigos mais específicos, por exemplo sobre avaliação e medidas, terão uma revista; haverá revistas mais voltadas para a área clínica. Com isso, a revista do Conselho fica mais livre para fazer aquilo que as outras não fazem, que é a discussão política de alguns temas. Isso não foi decisão de ninguém, foi uma evolução do País, do Sistema Conselhos, e chegamos ao ponto em que estamos agora. Meu único senão é, se você se restringe a isso apenas, você foge daquela definição inicial, e ela corre o risco de passar a ser mais uma revista só política, deixando de lado a função de formação.
O fato de que ela é muito usada nos cursos de graduação é uma beleza, significa que o Conselho está cumprindo a obrigação de zelar pela formação, o papel do Conselho é estar dentro dos cursos de Psicologia, onde o profissional começa. A partir do momento em que entra no curso de Psicologia, ele sabe que existe um código de ética e que ele está dentro do Sistema dos Conselhos. Não sei se respondi à sua pergunta, é assim que eu vejo. Minha participação inicial foi dar o pontapé com o que era possível e tentar direcionar a partir das escolhas que se faz. Depois, quando começa a funcionar, a própria revista atrai os artigos. E hoje se vê a quantidade de coisas publicadas, as mais variadas e realmente com muito envolvimento de alunos de graduação e pesquisa. Isso significa que os nossos programas de iniciação científica estão funcionando.

Antônio Marcos Chaves - Eu não teria muita condição de fazer avaliação das temáticas no período todo, apesar de ter recebido desde o número zero, que até outro dia eu tinha em casa, mas emprestei para uma colega e ela não me devolveu. Agora, como será republicado, eu recupero (risos). Mas a minha avaliação superficial é que a revista tem se aperfeiçoado cada vez mais, tem se tornado uma revista que atende o que ela se propõe, que são as questões profissionais e científicas. Acompanho a revista, sempre leio boa parte dos artigos e vejo que mesmo a estruturação, a organização da revista e a estruturação dos artigos têm sido aperfeiçoadas.

Marilene Proença - Também tenho um pouco essa dimensão da revista. Olhando o último número, de 2010, temos 3 relatos de experiência entre os 15 artigos que são publicados, e é muito difícil uma revista de qualquer outra área ter essa característica. Quem teve a experiência como editor sabe que, geralmente, temos de solicitar a alguém que encaminhe um relato de experiência, e aqui temos uma presença. Desde a época em 
que eu estava na editoria, em que vieram muitos relatos de experiência, temos até que ir dimensionando isso a cada número da revista para que ele não tome um espaço maior do que poderia, para dar esse equilíbrio de temas. O que tenho percebido é que há a tendência de, embora ela traga relatos de pesquisas e traga questões também ligadas à profissão, os temas serem muito críticos. Tenho observado, quando recebo a revista e olho a diversidade de temas, que se discutem questões que são candentes em cada uma das áreas da Psicologia. Acho que essa é uma tendência que a revista manteve. Mesmo não sendo mais editora, também é muito comum as pessoas me dizerem, "Olha, eu tenho este artigo, você acha que é interessante mandar para a revista, porque vai discutir esse tema?", quer dizer, as pessoas a identificam como uma revista que publica temas que tenham perspectiva mais ligada às discussões da ciência e da profissão, e isso reforça mais ainda esse lugar da revista.

Uma questão que esqueci de mencionar refere-se ao fato de que o GT, ao propor os meios de divulgação para os psicólogos, permitiu que fosse criada outra versão da revista Psicologia: Ciência e Profissão, que é a revista Diálogos. Ela passou a ser Diálogos - Ciência e Profissão. Conta, inclusive, com o logo da revista Psicologia: Ciência e Profissão, e apresenta o caráter de magazine, uma revista de divulgação que daria conta dos grandes temas políticos, tais como área do trabalho, questão de álcool e drogas, direitos humanos, abordando temáticas que são importantes para serem aprofundadas em um número temático. Então, existe toda uma discussão de não perder esse lugar do debate político mais aprofundado e temático. Outra coisa interessante é sempre trazer, ao final da revista, um professor homenageado, um psicólogo homenageado, porque isso vai construindo um registro da memória da Psicologia brasileira. É decisão do plenário quem são os nomes, quem são os professores homenageados para a revista também ter caráter nacional, não ficar restrita a apenas uma Região do Brasil e para garantir, em cada um dos números, que esse personagem, esse profissional que atuou em uma das áreas da Psicologia tenha um pouco da sua história registrada dentro da revista. Acho que essa é uma característica bem interessante da revista Psicologia: Ciência e Profissão.

João Cláudio Todorov - Vou fazer um comentário que não tem nada a ver com isso, para lembrar. Estava em uma banca de professor titular da Universidade de São Paulo (USP), na qual duas das professoras mais antigas estavam se candidatando a professor titular e tinham que fazer um memorial. $\mathrm{Na}$ hora em que vi o memorial, pensei: tenho que publicar isso, porque conta toda a história do início da análise de comportamento na USP via a história delas. Então, criamos, na Revista Brasileira de Análise e Comportamento, uma sessão-memórias, e temos publicado isso. Acho que valia a pena, em termos da revista, olhar e prever algo assim. Alguns já morreram. Mas eu gostaria de saber se o Paulo Rosas alguma vez fez um memorial para algum concurso, ele deve ter feito. Um memorial é a pessoa falando, contando a vida dela profissional e científica, é fantástico.

Iracema Neno Cecílio Tada - Marilene, eu queria que você contasse o impacto que houve quando a revista deixou de ser publicada em papel, deixou de ser enviada para todos os psicólogos, com relação até aos próprios autores, às pessoas que publicavam. Isso influenciou, diminuiu? Que análise você faz desse impacto na hora em que ela começa a ser eletrônica?

Marilene Proença - Talvez a Acácia tenha sofrido mais o impacto do que eu, porque já era o meu último ano de editoria quando a revista passou a ser eletrônica. Na época, foi muito interessante, porque eu, como editora, e o Sérgio (Leite), que tinha sido o 
As revistas

eletrônicas estão

aí e realmente são o futuro.

\section{João Cláudio}

Todorov editor anterior, trocávamos muitas ideias em relação a isso. Fomos a esse evento da UnB para conhecer essa questão das revistas eletrônicas e começamos a conversar com alguns editores que já estavam implantando formatos eletrônicos; um deles foi o professor Norberto Abreu, da Universidade de Brasília $(U n B)$, que estava à frente da revista de Psicologia da UnB. Ele contou que a revista, depois que assumiu o formato eletrônico, - não deixou de ser em papel, mas foi inserida eletronicamente -, estava sendo mais procurada para assinatura e em número de artigos. Ao mesmo tempo, na Universidade Federal de Minas Gerais (UFMG), o professor Miguel Mafhoud lançava a primeira revista só em formato eletrônico, a Memorandum. Era uma experiência nova e ele estava muito contente com a quantidade de artigos que estava recebendo pelo fato de a revista ter esse formato novo. E as pessoas estavam interessadas em conhecer. Isso foi nos dando um certo alento, porque começamos a pensar que seria uma novidade, as pessoas estão aderindo a ela, não é algo que vai desmontar ou desestruturar uma revista que já vinha sendo publicada há tantos anos somente em um formato, e também esse encanto das formas de submissão online, do acesso das pessoas no Brasil inteiro a isso, a forma como os pareceristas teriam acesso a esse material. Até esse momento, trabalhava-se muito com papel, eram pareceres em papel e eram feitas longas planilhas em papel. Parecia muito mais inteligente ter outra forma de submissão, outra maneira mesmo de organizar todo esse material que não da forma como acabávamos fazendo, tendo só o papel como alternativa. Acho que todo esse encanto das experiências bem-sucedidas e das novas tecnologias foi nos dando esse alento de que era uma fase de transição e de que isso, de alguma forma, seria bem assimilado pelos psicólogos. Mesmo assim, foi feita enorme divulgação, em todos os jornais, das várias formas de fazer chegar a informação ao psicólogo a respeito dessa mudança. Naquela ocasião, pusemos as revistas em formato eletrônico, no site do Conselho Federal de Psicologia, porque ainda não estávamos numa base de dados eletrônica, o PePsic não existia. Fizemos uma versão eletrônica da revista e a colocamos ali como uma experiência, também. Medíamos os acessos, de que foi registrado grande número, inclusive do exterior. Isso foi nos dando elementos, indícios, de que era um caminho meio sem volta, esse da versão eletrônica, mas que também não poderíamos abrir mão do papel, que ainda tinha um lugar importante na revista e que não poderia deixar de ser ocupado. Talvez a Acácia tenha outros impactos.

\section{Acácia Aparecida Angeli dos Santos -}

De fato, percebemos que muitas pessoas acreditavam que a revista tinha deixado de ser publicada. Embora tivesse havido a preocupação de divulgar a mudança, isso não foi suficiente num primeiro momento, tanto que o XIII plenário do CFP, a gestão de 2005 a 2007, tomou a decisão de publicar não apenas os cinco mil exemplares, mas quinze mil, e mandávamos um número grande para as universidades; era uma maneira de pelo menos mostrarmos a revista para cada professor, por exemplo, que recebia um exemplar lá na sua universidade, não mais na sua casa. Os coordenadores de curso recebiam pacotes grandes para distribuir para todos os professores, e acho que, com isso, começamos a perceber, de 2005 em diante e a atual comissão editorial tem acompanhado - um aumento de submissão de artigos a cada ano. Como disse a Marilene, foi importante ter ido para a base de dados PePsic, hoje temos a nossa coleção inteira disponível ali, mas também os números em papel continuam sendo impressos. Atualmente, são $5 \mathrm{mil}$ exemplares que vão para os autores, para a nossa comissão editorial, para o conselho consultivo. Fizemos uma mudança, criamos o que chamamos de conselho consultivo, antes eram só pareceristas ad hoc, hoje trabalhamos com um grupo ampliado de pesquisadores 
que colaboram conosco, provenientes de diversas áreas. A preocupação com a diversidade existe. Temos artigos que são de pesquisadores que trabalham inclusive com pesquisa básica, o número é bem pouco expressivo, digamos, mas existe, e existe muito de Psicologia aplicada, mas aparecem artigos teóricos e artigos de pesquisa empírica, e é uma preocupação manter o espaço para os relatos de experiência, nunca, jamais abrindo mão do ad hoc, quer dizer, o conselho consultivo é grande, mas em cada último número de um volume, saem todos os nomes dos pareceristas ad hoc que colaboraram.

Paulo Menandro - Só para fazer uma brincadeira: antigamente se procurava autor, agora se procura ad hoc.

João Cláudio Todorov - Atualmente, publicam-se poucos artigos de pesquisa básica porque há outros espaços onde eles podem ser publicados. Por falar nisso, a última (criação) minha não é a Revista Brasileira de Análise Comportamental, agora é uma eletrônica chamada Psicologia IESB, com conselho editorial nacional, e que está indo muito bem; é impressionante o número de consultas que recebe. As revistas eletrônicas estão aí e realmente são o futuro. A minha sugestão é que o CFP mande um e-mail para cada psicólogo inscrito e em dia, dizendo "saiu o número tal", e mande o link, de tal maneira que a pessoa só tem que clicar ali e vai para a revista, porque senão eles não vão acessar. Então, você perde leitores, porque as pessoas não estão acostumadas a dizer "deixe-me ver se tem alguma coisa lá".

Henrique Figueiredo Carneiro - Ouvir esse recorte de história da editoria da revista me fez pensar sobre o cuidado com a revista que, na verdade, pode ser dimensionado em cada época. Quando avaliamos o periódico hoje em dia, pensamos em qual é o Qualis desse periódico. Isso virou uma grande paranóia, como o meu periódico vai ser classificado no Qualis. A revista Psicologia: Ciência e Profissão vem sendo muito bem avaliada. Em cada período, como foi esse cuidar da revista pelas editorias?

João Cláudio Todorov - Primeiro, o cuidado com o próprio conselho editorial, pois é necessário ter pessoas com formação adequada para fazer isso, e os referidos ad hoc. Acho que a revista é boa, e ela começou bem, modéstia à parte, por essa preocupação de que tinha de ser não uma revista de divulgação de qualquer coisa, mas de que precisava haver uma seleção de qualidade. O que garante a boa aceitação da revista é a qualidade que se mantém na publicação.

Antônio Marcos Chaves - No período que relatei, havia a preocupação de qualificar os artigos. Não tenho certeza se havia consultores ad hoc, mas a avaliação, acredito que era feita pelo conselho editorial. Cada artigo era lido por dois membros, e depois nos reuníamos novamente e decidíamos quais seriam publicados. Se líamos, é porque provavelmente não havia nenhum parecer vindo de fora. A preocupação naquele momento foi a da regularidade de publicação, que é um dos itens de avaliação do Qualis, e, é lógico, as chamadas de artigos, que tentavam atrair mais profissionais para publicação na revista.

Marilene Proença - Acho que a revista sempre refletiu a política do Conselho, nas suas diversas plenárias. Na plenária em que eu estava, de 2002, o presidente do Conselho era Odair Furtado, e existia uma discussão que já tinha acontecido também em plenárias anteriores de que essa comissão editorial fosse composta por representantes de Regiões do Brasil, garantindo a presença de cada Região, e não de cada Conselho Regional. Teria que haver um acordo entre os Conselhos para indicar um nome que representasse cada Região; isso fazia também com que houvesse 
Acho que a revista vem no bojo dessa discussão da política vigente, e tem sido muito feliz a forma como tem dado conta. Sua avaliação mostra isso, bem como sua inserção na base de dados SciELO, que é muito importante e de grande visibilidade nacional e internacional.

Marilene Proença necessidade de conversa entre os diversos Regionais para que alguém fosse indicado, e isso era interessante, porque essa pessoa não vinha apenas como um conselheiro, um participante da comissão, mas como uma pessoa que representava determinada Região. E outra coisa que havíamos decidido é que os prêmios monográficos realizados deveriam ter um espaço de publicação na revista. Publicávamos os três primeiros lugares, que eram textos de profissionais e estudantes de Psicologia - os prêmios eram dados para duas categorias. No último número da revista em ano no qual havia o prêmio, publicávamos os vencedores e às vezes também algumas menções honrosas. Nesse sentido é que digo que ela é fruto da política do Conselho, que, em certo momento, inseriu essa questão do prêmio também como atividade da revista; em outros momentos, esse prêmio passa a não estar mais atrelado a ela.

A questão do formato dessa comissão editorial e das temáticas, as questões que foram sendo inseridas, a necessidade de se manter sempre a experiência como um item importante da revista, creio que foram várias situações, pelo menos nessa última década - a gestão do Sérgio Leite, que depois continuamos, e a de Acácia -, que refletem muitas das discussões do plenário. A própria constituição desse grupo de trabalho que contei se deveu a certa insatisfação com os meios de divulgação do Conselho para os psicólogos e para repensá-los.

Acho que a revista vem no bojo dessa discussão da política vigente, e tem sido muito feliz a forma como tem dado conta. Sua avaliação mostra isso, bem como sua inserção na base de dados SciELO, que é muito importante e de grande visibilidade nacional e internacional. É até curioso, porque, em princípio, a revista de um Conselho profissional poderia ter outro caráter, mas ela consegue articular aquilo que academicamente é exigido para ter uma avaliação compatível com revistas de alta qualidade, e, ao mesmo tempo, não perde as suas características e responde à política de uma instância, que é o Sistema Conselhos, que, de alguma forma, se vê representada pela sua comissão editorial e pela sua editora.

\section{Acácia Aparecida Angeli dos Santos - O} pedido aos Regionais para que encaminhem nomes para compor a comissão editorial vai com critérios. Cada um dos que estão aqui presentes foram indicados, escolhidos entre os Conselhos que compõem as regiões Sudeste, Centro-Oeste, Nordeste, Sul e Norte, mas com o perfil de alguém que pode compor a comissão editorial. Tem de ser pesquisador, tem de ser Doutor, tem de publicar, tem todo um perfil, diferentemente da revista Diálogos, para a qual pedimos pessoas com outro perfil: psicólogos que têm atuação mais marcante na área profissional. Cada Conselho indica inicialmente um nome, depois é realizada reunião telefônica entre os Regionais da Região e chega-se a um consenso sobre o nome indicado pela Região. É importante frisar isso, a comissão é composta com base nesses critérios, e não por uma livre indicação sem que haja o detalhamento do perfil das pessoas que vão compor essa comissão editorial.

Paulo Menandro - A revista do Conselho tem um suporte financeiro que a diferencia das demais, tanto que ela passou a ser eletrônica e continua sendo a revista que tem a maior quantidade de revistas impressas ainda. E ela certamente se manterá como uma revista de natureza geral, que não especifica áreas da Psicologia, nem orientações, e não é possível que uma revista do Conselho deixe de ser assim. Ao mesmo tempo, percebemos que está se abrindo no País um caminho um pouco diferente para outras publicações; têm surgido diversas revistas específicas, e algumas das revistas gerais, várias delas já com mais de vinte anos, também estão adotando uma diferenciação, definindo objetivos mais 
específicos. Em um movimento desse tipo, já que nenhuma outra sociedade nacional tem uma revista geral do mesmo porte, existe o risco de uma revista geral como a do Conselho tornar a receber artigos de segunda linha? Os de primeira linha seriam todos encaminhados para as revistas específicas? Vocês acham que isso seria um risco?

João Cláudio Todorov - Acho que é um risco, mas não pelos motivos que você colocou. Se as gerais começam a se especializar, aqueles ótimos artigos que iriam para a geral, mas que não estão dentro da nova especialização, terão a revista do Conselho para ser publicados. Por esse raciocínio, pode-se melhorar a qualidade dos artigos que vêm para cá. Meu último artigo na Psicologia, Reflexão e Crítica recebeu dois pareceres, um violento, antibehaviorista, mas feito de uma forma primaríssima, foi até fácil responder (risos). Se você der uma olhada no perfil, a (revista da Universidade) Federal do Rio Grande do Sul provavelmente terá, cada vez menos, artigos de análise de comportamento na revista de lá, assim também como é difícil publicar qualquer coisa nessa área na UnB, porque a UnB tem todo um sistema de cotas, não pode ter mais de $20 \%$ de artigos da casa, e esses artigos têm que ter uma distribuição percentual pelas mil e uma linhas de pesquisa. Não vejo problema de queda na qualidade, pelo contrário; se conseguirmos manter esse caráter geral, pode até aumentar.

Por falar nisso, nunca publiquei um artigo submetido na revista Psicologia: Ciência e Profissão, todos foram convites. Um dos meus mais importantes artigos saiu aqui, foi por convite do Jairo Eduardo BorgesAndrade, porque ele soube que eu estava publicando na revista Humanidades, da UnB, uma análise da Constituição brasileira como metacontingência; era um conceito novo que estava aparecendo e saiu republicado na Psicologia: Ciência e Profissão com cem mil exemplares. Ele disse que o artigo levou quinze anos para ter alguma repercussão; só em 1992 o pessoal da PUC de São Paulo publica sobre o mesmo conceito, mas eles não sabiam que eu tinha publicado quinze anos antes, e a explicação é que não são psicólogos e não recebem a revista do Conselho. A outra foi um debate sobre pesquisa e participação política, algo do qual o Isaías Pessotti, o Jairo e eu participamos, que foi gravado, e saiu o artigo como se fosse de autoria dos três. O terceiro será esse agora, também por convite. Eu ainda submeto um artigo! (risos)

Antônio Marcos Chaves - Acho também que há riscos, eu especularia que, à medida que as revistas se tornem mais especializadas e haja um aumento do número de produtores de artigos, as revistas gerais podem tender a melhorar a qualidade, à medida que se produzem mais artigos gerais por mais gente, artigos que não podem ser encaminhados para revistas específicas.

Marilene Proença - É provocativa essa questão do Paulo. Eu tendo um pouco a considerar que a revista, no momento em que se encontra, tem certa representação social entre os profissionais, entre aqueles que nela publicam, e que os temas que ela aceitaria melhor são os temas ligados à ciência e à profissão. Então, a busca pela revista é menos no sentido da temática, de o artigo ser mais específico ou mais geral, e mais em trazer questões ligadas a essa relação entre ciência e profissão. Parece-me que hoje ela se consolida nacionalmente como uma revista que é identificada por essa via, embora evidentemente saibamos que, tendo avaliação A nacional e estando em uma base de dados como a SciELO, duplica o número de artigos que são encaminhados à revista, já que muitas pessoas começam a encaminhar artigos pela qualidade da revista, porque ela tem essa boa nota, e, portanto, ter um artigo publicado nessa revista seria muito valorizado do ponto 
Uma coisa

que talvez

valha a pena

ser publicada

é convencer

os editores,

principalmente,

de que o parecer

tem que ser

didático.

\section{João Cláudio}

Todorov de vista acadêmico. Corremos também esse risco, evidentemente, quando estamos entre as revistas de melhor qualidade de avaliação, mas acho que esse perfil ainda é o que predomina, e, por isso, talvez não haja esse risco de haver artigos de categorias diferentes, até porque há uma competição muito maior, isto é, para selecionar 15 artigos entre 200, é necessária uma análise muito apurada.

Antônio Marcos Chaves-Na fala da Marilene, fiquei pensando que a especificidade da revista vai ser a articulação ciência e profissão, e não os temas gerais.

Paulo Menandro - Nós tínhamos pensado também em perguntar sobre a existência de alguma situação curiosa, dessas que editores vivem, situações anedóticas em relação a qualquer das etapas do trabalho como editor. Será que alguém se lembra de alguma?

João Cláudio Todorov - A única coisa de que lembro é da minha surpresa quando estava pensando em fazer o número um, chamar artigos, e, de repente, já tinha a História da Psicologia do Brasil pronta pelo Rodrigues para publicar, e tivemos que fazer o número zero sem passar pelo conselho editorial.

Paulo Menandro - Tanto o Rodrigues como o Paulo Rosas faziam parte do conselho editorial naquele momento, naquele primeiro conselho?

João Cláudio Todorov - O Paulo Rosas estava no conselho editorial indicado pelo CRP de Pernambuco, e o Rodrigues, indicado pela Bahia.

Marilene Proença - Lembro-me de algumas situações em relação aos pareceristas, porque essa relação do editor com o parecerista é muito tensa. Quando começou a funcionar a comissão editorial, reuníamonos e íamos ler os pareceres. Havia situações em que os colegas da comissão editorial ficavam impressionados com o parecer e se manifestavam: "Nossa, quem deu esse parecer? Parecer de uma única linha negando o manuscrito". Ficávamos desesperados, porque se tratava de um parecer que não era possível encaminhar ao autor. Aí procurávamos o nome do parecerista: fulano de tal. "Nossa, fulano de tal, não é possível, deveria estar muito mau humorado nesse dia, porque eu nunca vi um parecer dele em uma única linha". Em algumas situações, a comissão editorial revisava o artigo, levava para o hotel para lê-lo e no dia seguinte fazer uma discussão a partir daquele artigo com o grupo e em relação ao parecer, para se chegar a uma decisão sobre o manuscrito. Esses são alguns dos bastidores com relação aos pareceres, que são muito delicados. Outros vinham com linguagem absolutamente coloquial, diziam: "Mas isso é um absurdo, como é que alguém escreve um artigo deste?", e não podíamos mandar para o autor esse desabafo do parecerista. Essa era a parte mais tensa.

João Cláudio Todorov - Uma coisa que talvez valha a pena ser publicada é convencer os editores, principalmente, de que o parecer tem que ser didático. Se o artigo está ruim, a pessoa ou o grupo que o escreveu não fez aquilo para chatear o editor, certo? Mas muitos pareceristas reagem como se fosse uma ofensa pessoal. Quando convidamos o parecerista, ele tem que receber uma indicação - eu me lembro que fazíamos isso na Psicologia: Teoria e Pesquisa, o nome não é por acaso. Havia uma espécie de manual do parecer, lembrando que o papel do parecerista, mesmo que recusasse a publicação do artigo, era a de redigir o parecer em termos educados e como indicação do que poderia ser feito para melhorar. Não se pode tratar o artigo como algo a se jogar fora, ainda que você ache que seja muito difícil conseguir recuperá-lo, mas temos que dizer para o autor que, se ele conseguir atender as sugestões do parecerista, o artigo pode melhorar. O nosso papel não é punir as pessoas que mandam um artigo que não está adequado aos termos da revista, mas ser didático e ensinar como se faz um bom artigo. 


\section{Acácia Aparecida Angeli dos Santos}

- Lamentavelmente, não são os jovens pareceristas que fazem isso, às vezes são pareceristas que estão cansados, mau humorados, alguma coisa assim. Houve uma situação curiosa ocorrida no meu tempo aqui como editora. Alguém que recebeu o pedido de parecer comunicou-se diretamente com a Ana Bock, a presidente do CFP no XIII plenário, reclamando, indignado, para ela, como é que um editor da revista mandava um pedido de parecer nas férias do professor. Ela me repassou o e-mail, e eu apenas tomei conhecimento da reclamação. Nesse caso, não havia mais o que fazer...

Marilene Proença - Para mim, esse encontro de editores é a realização de um sonho do $12^{\circ}$ plenário do Conselho Federal de Psicologia. Quando eu estava na editoria, a revista Psicologia: Ciência e Profissão completou 25 anos, e existia esse desejo do grupo de que todos os números da revista fossem digitalizados, de que fossem colocados à disposição de todos os psicólogos, que se resgatasse essa história da revista. Quero parabenizar o 14을 plenário que, tendo à frente da editoria a coordenação da Dra. Acácia, conseguiu colocar esse projeto de fato em voga, o de efetivar a digitalização das revistas. São pouquíssimas as revistas que têm essa história e que conseguem dar conta dessa tarefa, embora, acho que o Paulo Menandro lembrou bem, a estrutura que o Conselho tem é muito favorável nesse sentido, mas você tem que ter gente que faça, e é realmente necessária uma decisão política de realizar essa tarefa. Então, quero parabenizar a Acácia e o $14^{\circ}$ plenário por terem efetivado essa comemoração dos 30 anos da revista Psicologia: Ciência e Profissão.

\section{Acácia Aparecida Angeli dos Santos -} Gostaria de ouvir uma palavra final dos entrevistadores e dos entrevistados, e, antecipadamente, agradeço pelo empenho de todos em estar aqui hoje.
Antônio Marcos Chaves - Eu queria agradecer imensamente pelo convite para participar dessa reunião, dizer que me senti bastante confortável e que achei a reunião muito agradável.

João Cláudio Todorov - Também isso. É um prazer enorme voltar ao Conselho, rejuvenesce a gente um pouquinho. Estou ficando velho, mas me recuso. Gostei de uma definição de velho: velho é alguém que tem cinco anos a mais que você. Mas voltar e discutir essas coisas faz bem, porque reanima e motiva. Eu continuo pelejando, e agora que me aposentei, tenho dois hobbies, um é golfe, e o outro é o meu curso de Psicologia do lesb. Quando saí da reitoria da UnB, fui para o governo, montei o Programa de Educação e Reforma Agrária que está aí firme e forte, e depois fui montar o mestrado e o doutorado da Católica de Goiás; paralelamente, comecei o curso de Psicologia do IESB, e o que me diverte realmente é isso, trabalhar diretamente com alunos. Estou recomeçando a iniciação científica, temos um bom exemplo de que iniciação científica funciona. Tenho mantido essas atividades, até porque a saúde já não dá para muita coisa, mas, de vez em quando, voltar e ver que a moçada continua é muito bom.

Marilene Proença - Eu gostaria de agradecer o convite da Acácia, da comissão editorial, do grupo todo, que, de alguma forma, teve essa ideia tão simpática de nos convidar, de podermos lembrar um pouco essa história e registrá-la. A meu ver, a revista, pelo que pudemos contar aqui, coincidentemente com uma pessoa que ocupou o lugar de editor em cada uma das décadas da revista, reflete todo esse caminho que a Psicologia tem percorrido no Brasil. Ela é um retrato da Psicologia no Brasil e, com certeza, aqueles que irão nos suceder na construção da Psicologia terão oportunidade de nos analisar e de pensar o que nós representamos, no final de contas, para esse conjunto, para essa história da Psicologia. É uma grande satisfação vermos o 
Lembro-me de que, logo que

saiu a decisão de ela ficar online, eu tinha alguns trabalhos no interior do Estado do Mato Grosso do Sul, e ia a uma cidade já quase na fronteira com o Paraguai que tem uma única psicóloga. Ela disse: "Uai, e agora, como é que eu vou saber o que é que o povo está falando?" Esses dias nos encontramos novamente, e perguntei a ela: "Você sabe?" Ela disse que sabia: "Agora eu já sei onde é que estão os botões".

Inara Barbosa Leão trigésimo ano, acompanharmos os temas que estão aqui, as questões que estão colocadas no interior da Psicologia e, ao mesmo tempo, olhar os desafios que ainda temos pela frente como ciência e profissão. E saber que poderemos, sem dúvida nenhuma, contribuir ainda mais para que essa discussão avance e para que a formação dos novos psicólogos tenha no seu interior pelo menos parte dessa discussão que temos constituído nas nossas áreas. Então, agradeço muito à Acácia pelo convite e ao Conselho Federal de Psicologia.

Inara Barbosa Leão - Quero fazer coro com a Acácia nos agradecimentos, pela aceitação do convite, pela presença de vocês, e dizer que, à medida que eu ouvia os depoimentos, ficava imaginando o que foi realmente a circulação da revista nesses trinta anos. Parece-me que essa dupla relação do que ela produziu e de como foi produzida tem um reflexo importante. Lembro-me de que, logo que saiu a decisão de ela ficar online, eu tinha alguns trabalhos no interior do Estado do Mato Grosso do Sul, e ia a uma cidade já quase na fronteira com o Paraguai que tem uma única psicóloga. Ela disse: “Uai, e agora, como é que eu vou saber o que é que o povo está falando?" Esses dias nos encontramos novamente, e perguntei a ela: "Você sabe?" Ela disse que sabia: "Agora eu já sei onde é que estão os botões". Realmente, a revista teve essa capacidade, como o professor Todorov estava dizendo, de levar as coisas do Conselho. Acho que fez isso e mais um pouco, fez os psicólogos de fato entenderem que havia questões que estavam preocupando, que estavam sendo discutidas. Também como psicóloga temos que agradecer a vocês que passaram por todo esse tempo; essa comemoração também tem esse caráter de podermos nos lembrar dessa construção e dizer que foram vocês também que a fizeram.

Iracema Neno Cecílio Tada - Queria agradecer a oportunidade de poder estar aqui vivenciando esse momento. Fui aluna do professor Todorov, fui aluna da Marilene.
As informações que foram relatadas neste momento ímpar possibilitam ao outro perceber os caminhos da seriedade em um processo de construção de uma revista e o quanto pequenos detalhes que passam despercebidos precisam ser considerados. Foram colocadas propostas extremamente interessantes para podermos fazer com que essa revista seja lida pelos profissionais formados, como a de enviar e-mail avisando sobre cada novo número. São indicações importantes para que essa revista que completa 30 anos complete mais 30 , mais 30, mais 30. Obrigada.

Paulo Menandro - Bom, eu queria primeiro avisar à Acácia que em julho estarei de férias! (risos). E agradecer pela presença da Marilene, do Antonio Marcos e do João Cláudio; a reunião foi ótima, trouxe uma série de informações muito interessantes. Gostaria, também, de contar uma história: no clube de golfe que o João Cláudio citou, existe um quadro com aquelas pontuações mais altas alcançadas, escrito Todorov. Ele diz que é ele, mas há controvérsias, porque pode ser um funcionário da embaixada da Bulgária. (risos)

Henrique Figueiredo Carneiro - Estou muito contente, porque também sou editor e aprendi muito ouvindo a história da Psicologia: Ciência e Profissão durante essas três décadas. Há aspectos que podemos, digamos, ventilar o que hoje estamos vivenciando em função da cobrança, que é muito grande para com as editorias, sobretudo no aspecto da avaliação. Uma revista que pertence a um Conselho ou a qualquer outra instituição universitária ou associativa, por exemplo, tem um peso muito grande em relação a isso. Pude hoje ouvir dos três convidados a perspectiva de cada época, e essa é uma grande riqueza, porque me atualiza e, sobretudo, me coloca também em uma perspectiva de desafio, já que hoje temos muitos meios, e, olhando para trás, percebemos os meios que cada um de vocês teve para lançar um projeto como esse, que é um projeto bem sucedido. Muito obrigado. 


\section{Acácia Aparecida Angeli dos Santos}

Doutora em Psicologia Escolar e do Desenvolvimento Humano pela USP

Professora da Graduação e da Pós-graduação Stricto Sensu em Psicologia da Universidade São Francisco, São Paulo - SP - Brasil

E-mail: acacia.angeli@gmail.com

\section{Antônio Marcos Chaves}

Doutor em Psicologia pela Universidade de São Paulo/ Pós-Doutorado em Psicologia Social pela

Universidade Aberta de Lisboa (Portugal). Professor Associado II Universidade Federal da Bahia,

Bahia - BH - Brasil

E-mail: amchaves@ufba.br/ips@ufba.br

\section{Inara Barbosa Leão}

Doutorado em Psicologia (Psicologia Social) pela Pontifícia Universidade Católica de São Paulo, SP - Brasil Professora de 3ํㅡㅁ Grau da Universidade Federal de Mato Grosso do Sul , MS - Brasil

E-mail: inarableao@hotmail.com

\section{Iracema Neno Cecilio Tada}

Mestre em Psicologia pela Universidade de Brasília

Professora da Universidade Federal de Rondônia, Porto Velho - RO - Brasil

E-mail: iracematada@ig.com.br

\section{Henrique Figueiredo Carneiro}

Prof. titular I, Universidade de Fortaleza - UNIFOR, Fortaleza, CE - Brasil

Realizando Estágio Sênior Pós-Doc no CERMES3-CESAME Université Paris V - Sorbonne, Paris, FR

E-mail: henrique@unifor.br

\section{João Cláudio Todorov}

Doutor em Psicologia pela Arizona State University. Coordenador do Curso de Psicologia do Instituto de Educação Superior de Brasília (IESB), Brasília - DF - Brasil

E-mail: joaoclaudio.todorov@gmail

\section{Marilene Proença Rebello de Souza}

Doutorado. Professora universitária

E-mail marileneproenca@gmail.com

\section{Paulo Menandro}

Doutorado em Psicologia Experimental) pela Universidade de São Paulo, SP - Brasil

Professor titular da Universidade Federal do Espírito Santo Espírito Santo - ES - Brasil

E-mail: paulomenandro@uol.com.br 